\title{
DURAÇÃO DO TESTE DE GERMINAÇÃO DO CAPIM-TANZÂNIA ${ }^{1}$
}

\author{
CAMILA DE AQUINO TOMAZ2; CIBELE CHALITA MARTINS'3; \\ LIDIA RAQUEL DE CARVALHO ${ }^{4}$; JOÃO NAKAGAWA ${ }^{5}$
}

\begin{abstract}
RESUMO - O trabalho foi realizado com o objetivo de determinar o tempo necessário para a condução do teste de germinação de Panicum maximum cv. Tanzânia. Trinta lotes de sementes foram avaliados pelo teste de germinação e para a identificação da data de término do teste foram realizadas contagens diárias do número de plântulas normais. No teste de germinação foram utilizados tratamentos de superação de dormência $\left(\mathrm{KNO}_{3}(0,2 \%), \mathrm{H}_{2} \mathrm{SO}_{4}(98 \% 36 \mathrm{~N})\right.$ ), temperaturas alternadas $\left(20-30{ }^{\circ} \mathrm{C}\right.$ e $\left.15-35^{\circ} \mathrm{C}\right)$ e foi ajustada uma curva de crescimento para a avaliação da germinação. Foi possível concluir que o teste de germinação do capim-tanzânia conduzido na alternância de temperatura de $15-35^{\circ} \mathrm{C}$ com fotoperíodo de $16 \mathrm{~h}-8 \mathrm{~h}\left(78 \mu \mathrm{mol} \mathrm{s}{ }^{-1}\right.$ $\mathrm{m}^{-2} / 8 \mathrm{~h}$ ) em substrato umedecido com $\mathrm{KNO}_{3}$ é o mais indicado por permitir máxima porcentagem de germinação (89\%) em menor tempo (quatro dias). Na alternância de temperatura de 20-30 ${ }^{\circ} \mathrm{C}$ as taxas de germinação atingem valores de $81 \%$ a $83 \%$ no período de cinco a seis dias e o tratamento com $\mathrm{H}_{2} \mathrm{SO}_{4}$ prejudica a taxa de germinação, independente da temperatura utilizada.
\end{abstract}

Termos para indexação: germinação, dormência, temperatura.

\section{DURATION OF GERMINATION TEST FOR TANZANIA GRASS}

\begin{abstract}
The objective of this study was to determine the time needed to conduct the germination test for Panicum maximum cv. Tanzania. Thirty seed lots were evaluated for germination and to identify the completion date of the test, daily counts of the number of normal seedlings were made. In the germination test, treatments for breaking dormancy $\left(\mathrm{KNO}_{3}(0.2 \%)\right.$, $\left.\mathrm{H}_{2} \mathrm{SO}_{4}(98 \% 36 \mathrm{~N})\right)$, and alternating temperatures $\left(20-30{ }^{\circ} \mathrm{C}\right.$ and $\left.15-35^{\circ} \mathrm{C}\right)$ were used and a growth curve for germination evaluation was adjusted accordingly. It was concluded that the germination test of Tanzania grass at alternating temperature of $15-35{ }^{\circ} \mathrm{C}$ with a photoperiod of $16 \mathrm{~h}-8 \mathrm{~h}\left(78 \mu \mathrm{mol} \mathrm{s} \mathrm{s}^{-1} / 8 \mathrm{~h}\right)$, in a substrate containing $\mathrm{KNO}_{3}$, is the most suitable for obtaining the maximum percentage germination $(89 \%)$ in the shortest time (four days). At the alternating temperature of $20-30{ }^{\circ} \mathrm{C}$, germination rates reached $81 \%$ to $83 \%$ in five to six days. Treatment with $\mathrm{H}_{2} \mathrm{SO}_{4}$ adversely affected the germination rate regardless of the temperature.
\end{abstract}

Index terms: germination, dormancy, temperature.

${ }^{1}$ Submetido em 16/05/2009. Aceito para publicação em 20/03/2010. Parte
da dissertação de Mestrado do primeiro autor apresentada a UNESP/
Faculdade de Ciências Agronômicas/Campus Botucatu.
${ }^{2}$ Pós graduanda do Departamento de Produção Vegetal/Agricultura,
FCA/UNESP, CP. 237, CEP: 18610-307, Botucatu-SP, e-mail:
catomaz@fca.unesp.br.

${ }^{3}$ Professora colaboradora, Departamento de Produção Vegetal/
Agricultura, FCA/UNESP, CP. 237, CEP: 18610-307, Botucatu-SP, e-mail: cibele@fca.unesp.br.

${ }^{4}$ Professora assistente, UNESP/Instituto de Biociências/Campus Botucatu, CEP: 18618-970, Botucatu-SP, E-mail: lidiarc@ibb.unesp.br.

${ }^{5}$ Professor Titular aposentado, Departamento de Produção Vegetal/ Agricultura, FCA/UNESP, CP. 237, CEP: 18610-307, Botucatu-SP, E-mail: secdamv@fca.unesp.br. 


\section{INTRODUÇÃO}

Panicum maximum (Jacq.) é uma importante espécie forrageira devido ao alto potencial de produção de massa seca por unidade de área, adaptabilidade, qualidade de forragem, facilidade de estabelecimento e aceitabilidade pelos animais. Capins desse gênero movimentam aproximadamente $11 \%$ do mercado de sementes de forrageiras representando em torno de U\$ 27,5 milhões, dos quais U\$ 25 milhões são referentes às cultivares Tanzânia-1 e Mombaça (Andrade, 2001).

Quando comparado à implantação de pasto por mudas, a formação de pastagens com sementes pode ser considerada um método de menor custo e maior agilidade operacional e qualidade de serviços. Assim, torna-se importante a utilização de sementes de boa qualidade, com alta porcentagem de germinação e vigor (Lago e Martins, 1988).

Trabalhos com sementes de gramíneas forrageiras têm demonstrado que há possibilidade de reduzir o tempo recomendado para o teste padrão de germinação prescrito pelas Regras para Análise de Sementes (RAS) (Brasil,1992). Em análise de dados de 280 amostras de sementes de capim-colonião (P.maximum) não foram detectadas diferenças significativas entre o total de germinação aos 21 e aos 28 dias (Usberti, 1981). Dias e Alves (2001), concluíram que o teste de germinação de sementes de P.maximum e Brachiaria brizantha (Hochst. ex A. Rich.) Stapf pode ser encerrado aos sete e dez dias após a semeadura, respectivamente, sem comprometimento dos resultados. Gaspar-Oliveira et al. (2008) verificaram para a $B$. brizantha $\mathrm{cv}$. Marandu que o teste de germinação pode ser encerrado aos 11 dias, caso seja conduzido na temperatura alternada de $20-35{ }^{\circ} \mathrm{C}$ e com sementes escarificadas com ácido sulfúrico. Maeda e Pereira (1997), em um trabalho realizado com sementes de Paspalum notatum (Flügge. Parodi), verificaram que foi possível reduzir de 28 para 14 dias o período do teste de germinação e a maior rapidez do teste mostrouse importante, também, para evitar a proliferação de fungos.

De acordo com as RAS (Brasil, 1992), o tempo recomendado para o teste de germinação de $P$. maximum é de 28 dias e pode ser prolongado por até 35 dias, se forem constatadas sementes dormentes. Esse período é considerado longo pelos laboratórios de análise, empresas, agricultores e pecuaristas que produzem e comercializam essas sementes, representando um problema para a escolha dos lotes por parte dos interessados em adquirir as sementes. Dessa forma, as escolhas na aquisição dos lotes são baseadas na intuição e experiência do comprador, no preço e nos resultados do teste de tetrazólio das sementes (Dias e Alves, 2008).

O teste de germinação tornou-se de uso generalizado na avaliação da qualidade fisiológica de sementes por permitir a obtenção de resultados reproduzíveis e comparáveis entre laboratórios (Marcos Filho et al., 1987). Dentre os fatores que afetam o processo germinativo, a temperatura influencia de três maneiras distintas: sobre o total de germinação, velocidade e uniformidade de germinação (Carvalho e Nakagawa, 2000). Para as sementes de $P$. maximum existem duas faixas de temperaturas alternadas consideradas ótimas e descritas pelas RAS para a germinação das sementes, que são de $20-30{ }^{\circ} \mathrm{C}$ e $15-35$ ${ }^{\circ} \mathrm{C}$. Esta última, também foi identificada como a mais favorável para esta espécie por Usberti (1981), Oliveira e Mastrocola (1984).

Além da utilização de temperaturas alternadas e de luz no teste de germinação de gramíneas forrageiras, as RAS (Brasil, 1992) também recomendam a utilização de tratamentos específicos para a superação da dormência. Para as sementes do gênero Panicum, é recomendada a imersão das sementes em ácido sulfúrico concentrado por cinco minutos e/ou o umedecimento do substrato com solução de nitrato de potássio a $0,2 \%$.

Essas informações são reforçadas por resultados de pesquisa sobre dormência que também sugerem para o $P$. maximum a escarificação ácida (Usberti et al., 1995), e o tratamento com $\mathrm{KNO}_{3}$ (Smith, 1979; Ellis et al., 1983; Martins e Silva, 1998). O efeito estimulador da germinação do tratamento com $\mathrm{KNO}_{3}$ é atribuído à sua ação oxidante (Ellis et al., 1983).

Entretanto, em alguns casos, a escarificação ácida pode não promover acréscimo significativo na germinação de sementes de P.maximum ou mesmo prejudicar o processo (Dias e Toledo, 1993; Previero et al., 1998; Martins e Silva 1998).

Assim, pela literatura consultada pode-se observar a necessidade de aprimorar os procedimentos de período de avaliação do teste de germinação e tratamentos de superação de dormência recomendado pelas RAS para se obter maior germinação de P.maximum em menor tempo, minimizando as atividades laboratoriais.

Objetivou-se com este trabalho determinar o tempo necessário à condução do teste de germinação para sementes de P.maximum cv. Tanzânia, estabelecendo o 
método de superação de dormência e a temperatura ideal.

\section{MATERIAL E MÉTODOS}

A pesquisa foi conduzida no Laboratório de Análise de Sementes do Departamento de Produção Vegetal Setor Agricultura da Faculdade de Ciências Agronômicas, da Universidade Estadual Paulista (UNESP), na Fazenda Experimental Lageado, em Botucatu - SP.

Foram utilizados 30 lotes comerciais de sementes fiscalizadas de Panicum maximum cv. Tanzânia de diversas procedências. Todos foram homogeneizados, submetidos à limpeza em peneiras e passagem em soprador pneumático complementado por separação manual para a obtenção de sementes puras. Os lotes apresentavam média de teor de água inicial de 10,2\%.

$\mathrm{O}$ teste de germinação foi conduzido com quatro subamostras de 100 sementes, semeadas sobre duas folhas de papel do tipo filtro umedecidas com água destilada, na quantidade 2,0 vezes a massa do papel (Brasil, 1992), dentro de caixas plásticas transparentes tipo gerbox colocadas individualmente em sacos plásticos de $0,05 \mathrm{~mm}$ de espessura para a manutenção da umidade do substrato (Gaspar-Oliveira et al., 2007). Foram consideradas plântulas normais aquelas cuja plúmula já havia ultrapassado o coleóptilo e a raiz primária estava com comprimento mínimo de $0,5 \mathrm{~cm}$, sendo as contagens realizadas diariamente até o $28^{\circ}$ dia, com acréscimo de sete dias, totalizando 35 dias que é o período máximo prescrito pela RAS (Brasil, 1992). Durante o teste de germinação, as sementes foram mantidas em duas condições de temperaturas alternadas de $15-35^{\circ} \mathrm{C}$ e de 20 $30{ }^{\circ} \mathrm{C}$, ambos com fotoperíodo de $16 \mathrm{~h}-8 \mathrm{~h}\left(78 \mu \mathrm{mol} . \mathrm{s}^{-1}\right.$ $\mathrm{m}^{-2} / 8 \mathrm{~h}$ ) e submetidas ou não (testemunha) aos seguintes métodos para a superação de dormência: umedecimento do substrato com $\mathrm{KNO}_{3}(0,2 \%)$, escarificação ácida mediante a imersão das sementes em $\mathrm{H}_{2} \mathrm{SO}_{4}(98 \% 36 \mathrm{~N})$ P.A. por cinco minutos seguidos de lavagem em água corrente e secagem à sombra (Brasil, 1992).

O teste de tetrazólio foi realizado com as sementes remanescentes do teste de germinação que foram seccionadas longitudinalmente e medianamente através do embrião. Uma das metades de cada semente foi imersa em uma solução de tetrazólio a $0,1 \%$ e mantidas em câmara escura, a $37^{\circ} \mathrm{C}$, por um período de 3 horas. Após esse período as sementes foram lavadas e a leitura feita imediatamente, classificando-se as sementes em viáveis e não viáveis (mortas) (Dias e Alves, 2001).
No procedimento estatístico, os 30 lotes foram considerados repetições para cada tratamento de superação de dormência $\left(\mathrm{KNO}_{3}, \mathrm{H}_{2} \mathrm{SO}_{4}\right.$ e sem tratamento) e cada condição de temperatura $\left(20-30{ }^{\circ} \mathrm{C}\right.$ e $\left.15-35^{\circ} \mathrm{C}\right)$. Para cada lote (repetição), foi ajustada uma curva de crescimento utilizando o modelo não linear para a avaliação da porcentagem de germinação. Por meio do modelo não linear logístico determinou-se o tempo necessário à condução do teste de germinação, calculando-se o valor a partir do qual a diferença entre a assíntota e a função estimada não foi estatisticamente significativa (Carvalho, 1996).

Foram ajustadas curvas para cada tratamento e cada temperatura utilizando o modelo: $y=\alpha /\left(1+\exp \left(-\beta+\gamma^{*} x\right)\right)$, onde " $\alpha$ " é a assíntota, representando a porcentagem de germinação, " $\beta$ " é o parâmetro de posição representando o deslocamento da curva, “ $\gamma$ ” está relacionado com a taxa de crescimento, que representa a velocidade de germinação, e " $x$ " representa o tempo necessário para a condução do teste. A análise de variância foi realizada utilizando o esquema fatorial em blocos para cada parâmetro da função $(\alpha, \beta, \gamma)$ e esses parâmetros foram substituídos na equação para o cálculo de " $x$ " (Carvalho, 1996). O ponto de estabilização da variável foi determinado pela regressão segmentada. Segundo Portz et al. (2000), o modelo de regressão segmentada consiste em duas partes: uma reta inclinada ascendente ou descendente seguida de uma linha horizontal, onde seus pontos de interseção vão determinar o ponto de estabilização. Este modelo de uma inclinação é mais adequado para estimar parâmetros de crescimento. Para outros tipos de variáveis biológicas, a equação do modelo de regressão segmentada descreve duas linhas de interseção, ambas com inclinação diferente de zero. O modelo de regressão utilizado é do tipo:

$Y_{i}=L+U\left(R-X_{L R i}\right)+e_{i}, \quad i=1,2 \ldots n_{i}, n_{i+1}, \ldots, n$; onde $\left(\mathrm{R}-\mathrm{X}_{\mathrm{LRi}}\right)=0$ para $\mathrm{i} \geq \mathrm{n}_{1}+1$, e $\mathrm{n}_{1}$ é o número de observações até o ponto de estabilização, e "n" é o número de pares de observações. Onde $Y_{i}$ representa a porcentagem de germinação, L representa o ponto máximo de germinação, $U$ representa o coeficiente de determinação, $R$ representa a data de estabilização, $X_{\text {LRi }}$ representa o tempo (dias) e "e. é o componente aleatório ou resíduo.

Os métodos de superação de dormência e as temperaturas foram comparados por meio da análise de variância em esquema fatorial ( 3 tratamentos $x 2$ alternância de temperaturas), realizada para cada parâmetro estimado pelo modelo da regressão logística para identificar quais tratamentos permitiram maior germinação no menor 
tempo. A comparação de médias foi realizada pelo teste de Tukey a $5 \%$ de probabilidade.

\section{RESULTADOS E DISCUSSÃO}

Para a construção de curvas de porcentagem de germinação, para os métodos de superação de dormência e para as temperaturas, verificou-se que os valores observados estavam próximos à curva dos valores estimados, indicando que os dados se ajustaram ao modelo de regressão logística $y=\alpha /\left(1+\exp \left(-\beta+\gamma^{*} x\right)\right)($ Figura 1$)$.

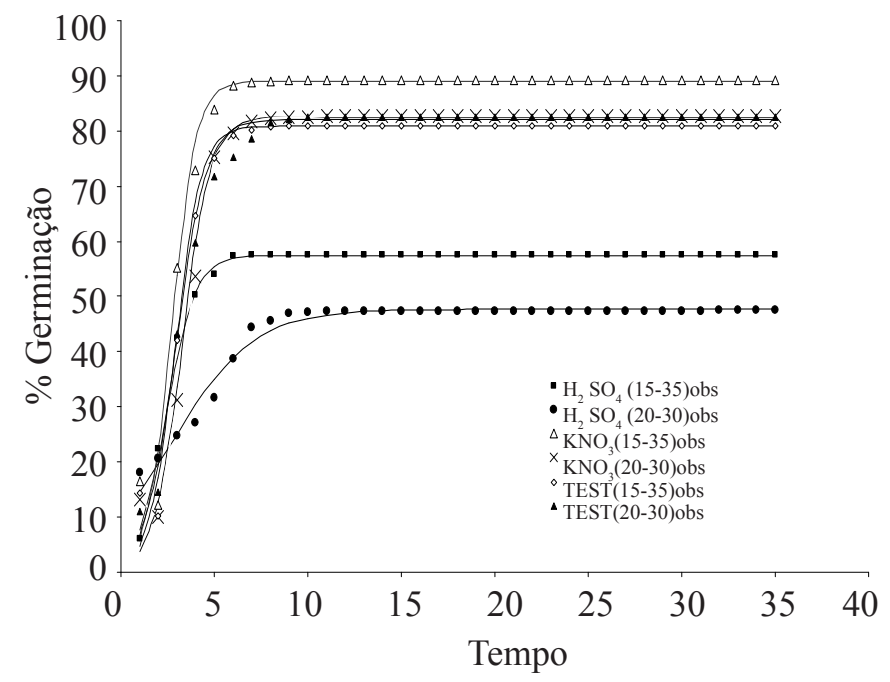

FIGURA 1. Valores médios observados por meio de curvas determinadas pelo modelo logístico $y=\alpha\left(1-\exp \left(-\left(\beta+\gamma^{*} x\right)\right)\right.$ para a porcentagem de germinação, para os métodos de superação de dormência $\left(\mathrm{H}_{2} \mathrm{SO}_{4}, \mathrm{KNO}_{3}\right)$ e testemunha $\left(15-35{ }^{\circ} \mathrm{C}\right.$ e $\left.20-30{ }^{\circ} \mathrm{C}\right)$, em função do tempo (dias) para $P$. maximum cv. Tanzânia.

Assim, na Figura 1, foi possível verificar que a partir do quinto dia de avaliação houve a estabilização das curvas das temperaturas, para o mesmo método de superação de dormência. As curvas permaneceram unidas na mesma faixa de porcentagem de germinação até o final do teste $\left(35^{\circ}\right.$ dia $)$, indicando que houve diferença para este parâmetro. Os menores valores de germinação foram obtidos com $\mathrm{H}_{2} \mathrm{SO}_{4}$ e alternância de temperatura $20{ }^{\circ} \mathrm{C}-30{ }^{\circ} \mathrm{C}$, A partir do quinto dia de avaliação verificou-se, para os tratamentos $\mathrm{KNO}_{3} \mathrm{e}$ testemunha diferenças de 20 pontos percentuais acima das curvas de $\mathrm{H}_{2} \mathrm{SO}_{4}$.

As estimativas da porcentagem de germinação $(\alpha)$, da data de estabilização da germinação $(\beta)$ e a velocidade de germinação $(\gamma)$, que se encontram apresentadas na Tabela 1. Entre os métodos avaliados para a superação da dormência observaram-se maiores valores de porcentagem de germinação $(\alpha)$, para o método $\mathrm{KNO}_{3} \mathrm{e}$ para testemunha do que para o $\mathrm{H}_{2} \mathrm{SO}_{4}$.

A menor porcentagem de germinação das sementes submetidas ao tratamento com $\mathrm{H}_{2} \mathrm{SO}_{4}$ ocorreu por causa da elevada taxa de sementes mortas após este tratamento. Dias e Alves (2001) verificaram que a escarificação com $\mathrm{H}_{2} \mathrm{SO}_{4}$ pode prejudicar a germinação de sementes de P.maximum sem dormência.

Corroborando essas informações, Toledo et al. (1995) verificaram que a escarificação das sementes de P.maximum com $\mathrm{H}_{2} \mathrm{SO}_{4}$ prejudicou a porcentagem de germinação desde o início até o final do período de armazenagem. Contudo, Usberti (1981), trabalhando com vários lotes de P.maximum, cv. Colonião relatou que houve aumento da porcentagem e velocidade de germinação das sementes que receberam pré-tratamento com ácido sulfúrico. Respostas diversas das sementes de P.maximum ao tratamento de escarificação com ácido sulfúrico podem ser atribuídas, também às diferenças de genótipos (Smith, 1979).

As sementes utilizadas no trabalho não apresentaram dormência, pois o teste de tetrazólio pode-se observar que as sementes remanescentes estavam mortas. O armazenamento das sementes e a colheita no chão fazem com que as sementes superem naturalmente a dormência, que ocorre com maior intensidade de frequência em sementes recém-colhidas e colhidas por outros métodos, como o da colheita mecânica no cacho (Grof, 1968; Renard e Capele, 1986; Maschietto et al., 2003).

Quanto à análise da velocidade de germinação $(\gamma)$, os resultados demonstraram que houve diferença significativa, no nível de $5 \%$ de probabilidade pelo teste de Tukey, apenas para as temperaturas no tratamento $\mathrm{KNO}_{3}$ e a menor velocidade de germinação ocorreu na temperatura de $20-30{ }^{\circ} \mathrm{C}$ (Tabela 1). A velocidade de germinação da testemunha foi semelhante ao $\mathrm{H}_{2} \mathrm{SO}_{4}$, de modo independente da temperatura, e também para o tratamento $\mathrm{KNO}_{3}$ na temperatura de $15-35^{\circ} \mathrm{C}$. 
TABELA 1. Estimativas da porcentagem de germinação $(\alpha)$, da data de estabilização da germinação ( $\beta)$ em dias após a semeadura e velocidade de germinação $(\gamma)$ com respectivos desvios-padrão referentes aos ajustes médios, segundo métodos de superação de dormência e temperaturas.

\begin{tabular}{|c|c|c|c|c|c|c|}
\hline \multirow{3}{*}{ Tratamento } & \multicolumn{2}{|c|}{ Porcentagem } & \multicolumn{2}{|c|}{ Estabilização (dias) } & \multicolumn{2}{|c|}{ Velocidade } \\
\hline & \multicolumn{2}{|c|}{$\mathrm{A}$} & \multicolumn{2}{|c|}{$\mathrm{B}$} & \multicolumn{2}{|c|}{$\gamma$} \\
\hline & $15-35^{\circ} \mathrm{C}$ & $20-30{ }^{\circ} \mathrm{C}$ & $15-35^{\circ} \mathrm{C}$ & $20-30^{\circ} \mathrm{C}$ & $15-35^{\circ} \mathrm{C}$ & $20-30{ }^{\circ} \mathrm{C}$ \\
\hline $\mathrm{H}_{2} \mathrm{SO}_{4}$ & $61 \pm 19$ a B & $47 \pm 13$ b B & $4 \pm 2$ a A & $5 \pm 6$ a A & $2 \pm 1$ a A & $1 \pm 1$ a A \\
\hline $\mathrm{KNO}_{3}$ & $89 \pm 10$ a $\mathrm{A}$ & $83 \pm 09$ a A & $7 \pm 3$ a A & $6 \pm 4$ a A & $3 \pm 1$ a $A$ & $2 \pm 1 \mathrm{~b} \mathrm{~A}$ \\
\hline Testemunha & $81 \pm 14$ a A & $82 \pm 12$ a A & $6 \pm 3$ a A & $6 \pm 3$ a A & $2 \pm 1$ a A & $2 \pm 1$ a A \\
\hline
\end{tabular}

Significativo a $5 \%(\mathrm{p}<0,05)$;

Dentro de cada parâmetro $(\alpha, \beta, \gamma)$, letras minúsculas comparam médias de temperatura para cada tratamento (linha) e letras maiúsculas comparam médias tratamento para cada temperatura (coluna).

Oliveira e Mastrocola (1984), em um trabalho realizado com sementes de Brachiaria humidicola (Rendle) Schweick, observaram que estas sementes germinaram melhor e mais rápido à temperatura alternada de $15-35{ }^{\circ} \mathrm{C}$ do que a $20-35{ }^{\circ} \mathrm{C}$, de forma semelhante do observado neste trabalho para o tratamento $\mathrm{KNO}_{3}$.

Também existem relatos na literatura sobre o aumento da velocidade de germinação de sementes de B.brizantha (Gaspar-Oliveira et al., 2008) e de P.maximum (Usberti et al.,1995) escarificadas com $\mathrm{H}_{2} \mathrm{SO}_{4}$, em comparação com as sementes não escarificadas.

A melhor condição para o teste de germinação de P. maximum foi obtida na temperatura de $15-35^{\circ} \mathrm{C}$ em semeadura sobre substrato umedecido com $\mathrm{KNO}_{3}$, pois, nessas condições obteve-se a máxima porcentagem de germinação final, de $89 \%$ e a maior velocidade de germinação, que possibilitou o encerramento do teste aos cinco dias após a data de instalação (Figuras 1 e 2), ou seja, antecipando em 23 dias a obtenção dos resultados em comparação à recomendação das RAS (Brasil 1992) e em data mais próxima aos 7 dias após a semeadura relatados por Dias e Alves (2001).

Os tratamentos testemunha em ambas as temperaturas testadas e $\mathrm{KNO}_{3}$ na alternância de temperatura de 20-30 ${ }^{\circ} \mathrm{C}$ apresentaram menor porcentagem de germinação do que o tratamento $\mathrm{KNO}_{3}$ na temperatura $15-35{ }^{\circ} \mathrm{C}$, pois os primeiros tratamentos citados apresentavam porcentagem média de germinação final entre 81 e $83 \%$ (Figuras 1, 3, 4 e 5) e, nesses tratamentos, o teste de germinação pôde ser encerrado entre 5 e 6 dias após a instalação. Os tratamentos de escarificação com $\mathrm{H}_{2} \mathrm{SO}_{4}$ foram os mais prejudiciais às sementes, pois nas temperaturas de $15-35{ }^{\circ} \mathrm{C}$ e $20-30{ }^{\circ} \mathrm{C}$ resultaram em porcentagens máximas de germinação de 57 e $47 \%$, respectivamente e o encerramento do teste situouse entre 4 e 8 dias (Figuras 1, 6 e 7). Essas informações confirmam relatos anteriores sobre o efeito prejudicial causado pela escarificação com $\mathrm{H}_{2} \mathrm{SO}_{4}$ sobre a germinação das sementes de P.maximum (Toledo et al., 1995; Martins e Silva 1998; Dias e Alves, 2001). A porcentagem de sementes viáveis após o término do teste de germinação aos 35 dias, identificadas pelo teste de tetrazólio, para todos os lotes apresentaram valores estatisticamente iguais a zero.

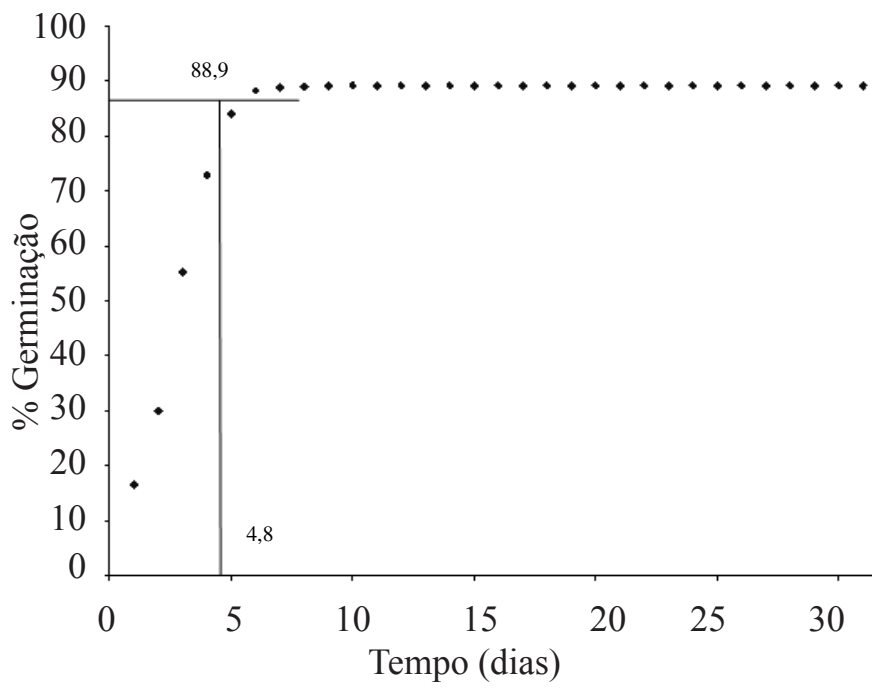

FIGURA 2. Ponto de estabilização da germinação acumulada ao longo do tempo (dias) no tratamento para $\mathrm{KNO}_{3}$ na temperatura

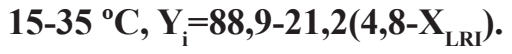




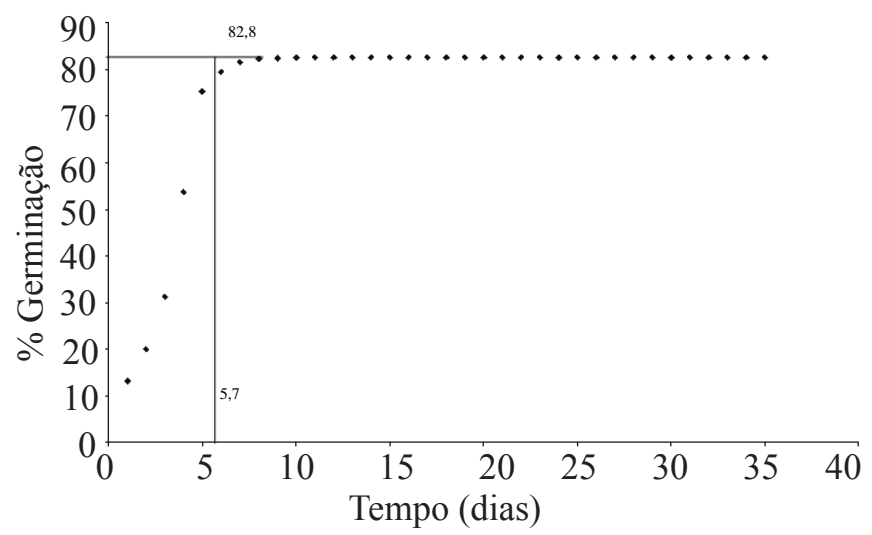

FIGURA 3. Ponto de estabilização da germinação acumulada ao longo do tempo (dias) no tratamento para $\mathrm{KNO}_{3}$ na temperatura

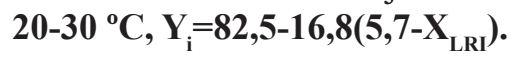

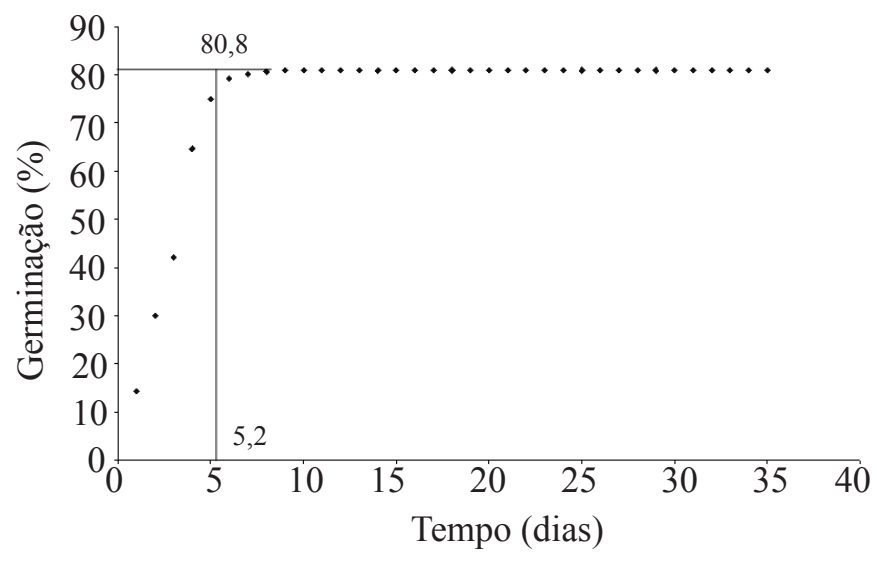

FIGURA 4. Ponto de estabilização da germinação acumulada ao longo do tempo (dias) para testemunha (sem tratamento) na temperatura

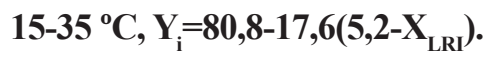

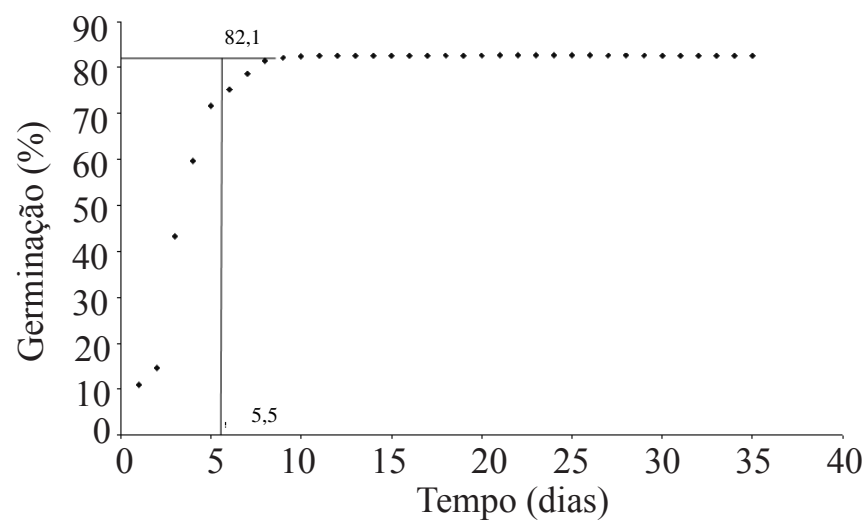

FIGURA 5. Ponto de estabilização da germinação acumulada ao longo do tempo (dias) para testemunha(sem tratamento) na temperatura 20-30 ${ }^{\circ} \mathrm{C}, \mathrm{Y}_{\mathrm{i}}=82,1-16,7\left(5,5-\mathrm{X}_{\mathrm{LRI}}\right)$.

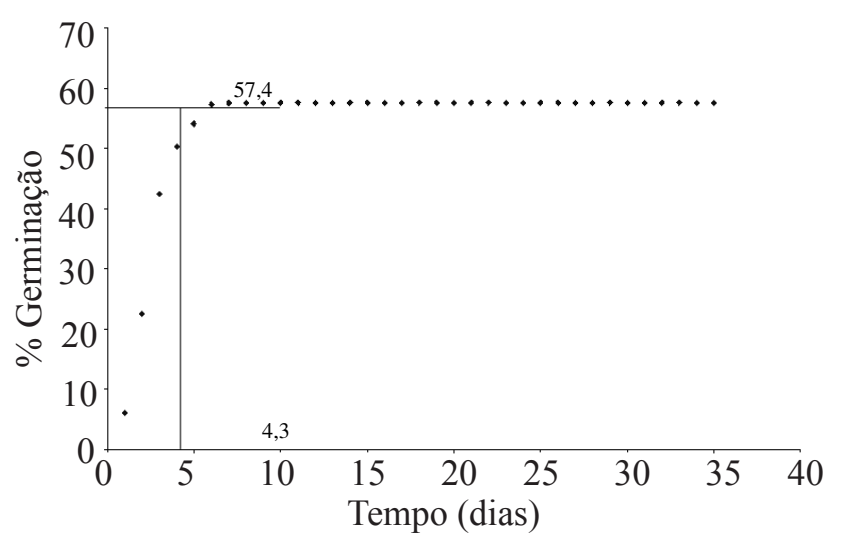

FIGURA 6. Ponto de estabilização da germinação acumulada ao longo do tempo (dias) no tratamento $\mathrm{H}_{2} \mathrm{SO}_{4}$ na temperatura $15-35$

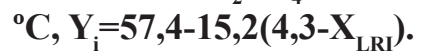

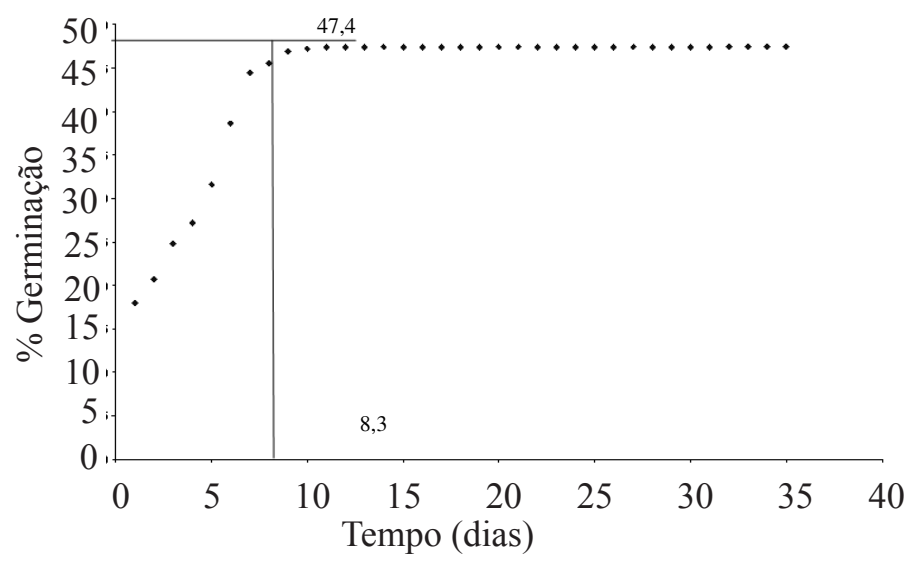

FIGURA 7. Ponto de estabilização da germinação acumulada ao longo do tempo (dias) no tratamento $\mathrm{H}_{2} \mathrm{SO}_{4}$ na temperatura 20-30 ${ }^{\circ} \mathrm{C}, \mathrm{Y}_{\mathrm{i}}=47,4-4,2\left(8,3-\mathrm{X}_{\text {LRI }}\right)$.

Contudo, deve-se destacar que a redução do tempo recomendado pelas R.A.S. (Brasil, 1992) para a conclusão do teste de germinação é viável para os métodos de superação de dormência e temperaturas, estudadas na pesquisa.

\section{CONCLUSÕES}

$\mathrm{O}$ teste de germinação de sementes de capim-tanzânia conduzido com alternância de temperatura de $15-35^{\circ} \mathrm{C}$ e 20-30 ${ }^{\circ} \mathrm{C}$, por $16 \mathrm{~h}-8 \mathrm{~h}$, em substrato umedecido com $\mathrm{KNO}_{3}$ é o mais indicado para se obter a máxima porcentagem de germinação em menor tempo (quatro e seis dias, 
respectivamente).

O tratamento com ácido sulfúrico, independente da alternância de temperatura, prejudica a taxa de germinação.

\section{AGRADECIMENTOS}

À Fapesp, Fundação de Amparo à Pesquisa do Estado de São Paulo, pela concessão da bolsa de estudos do primeiro autor.

\section{REFERÊNCIAS}

ANDRADE, R.P.de. Pasture seed production in Brazil. In: INTERNATIONAL GRASSLAND CONGRESS, 19., 2001, São Pedro. Proceedings... Piracicaba: Fundação de Estudos Agrários Luiz de Queiroz, 2001. p.129-132.

BRASIL. Ministério da Agricultura e Reforma Agrária. Secretaria Nacional de Defesa Agropecuária. Departamento Nacional de Defesa Vegetal. Coordenação de Laboratório Vegetal. Regras para análise de sementes. Brasília, DF, 1992. 365p.

CARVALHO, L.R. Métodos para comparação de curvas de crescimento. 1996, 172f. Tese (Doutorado em Agronomia) - Faculdade de Ciências Agronômicas Universidade Estadual Paulista, Botucatu, 1996.

CARVALHO, N.M.; NAKAGAWA, J. Sementes: ciência, tecnologia e produção. 4.ed. Jaboticabal: Funep, 2000, $588 \mathrm{p}$.

DIAS, D.C.F.S.; TOLEDO, F.F.de. Germinação e incidência de fungos em testes com sementes de Brachiaria brizantha Stapf. Scientia Agricola, v.50, n.1, p.68-76, 1993.

DIAS, M.C.L.L.; ALVES, S.J. Teste de tetrazólio em sementes de Panicum maximum e Brachiaria brizantha. IAPAR, Londrina, 2001. 11p. (Apostila)

DIAS, M.C.L.L.; ALVES, S.J. Avaliação da viabilidade de sementes de Panicum maximum Jacq. pelo teste de tetrazólio. Revista Brasileira de Sementes, v.30, n.3, p.152-158, 2008.

ELLIS, R.H.; HONG, T.D.; ROBERTS, E.H. Procedures for the safe removal of dormancy from rice seed. Seed Science and Technology, v.11, p.77-112, 1983.

GASPAR-OLIVEIRA, C.M.; MARTINS, C.C.; NAKAGAWA, J.; TOMAZ, C.A. Manutenção da umidade do substrato durante o teste de germinação de Brachiaria brizantha. Revista Brasileira de Sementes, v.29, n.3, p.
52-60, 2007.

GASPAR-OLIVEIRA, C.M.; MARTINS, C.C.; NAKAGAWA, J.; CAVARIANI, C. Duração do teste de germinação de Brachiaria brizantha cv. Marandu (Hochst. ex A. Rich.) Stapf. Revista Brasileira de Sementes, v.30, n.3, p.30-38, 2008.

GROF, B. Viability of seed of Brachiaria decumbens. Queensland Journal of Agricultural \& Animal Science, v.25, p.149-152, 1968.

LAGO, A.A. do.; MARTINS, L. Qualidade fisiológica de sementes de Brachiaria brizantha. Pesquisa Agropecuária Brasileira, v.33, n.2, p.199-204, 1998.

MAEDA, J.A.; PEREIRA, M.F.D.A. Caracterização, beneficiamento e germinação de sementes de Paspalum notatum Flügge. Revista Brasileira de Sementes, v.19, n.1, p.100-105, 1997.

MARCOS FILHO, J.; CÍCERO, S.M.; SILVA, W.R. Avaliação da qualidade das sementes. Piracicaba: FEALQ, 1987, 230p.

MARTINS, C.C.; SILVA, W.R. Superação da dormência de sementes de Capim Colonião. Planta Daninha, v.16, n.2, p.77-84, 1998.

MASCHIETTO, R.W.; NOVEMBRE, A.D.L.C.; SILVA, W.R. Métodos de colheita e qualidade das sementes de capim-colonião cv. Mombaça. Bragantia, v.62, n.2, p.291296, 2003.

OLIVEIRA, P.R.P.; MASTROCOLA, M.A. Longevidade das sementes de gramíneas forrageiras tropicais. Boletim Indústria Animal, v.41, p.203-211, 1984.

PORTZ, L. DIAS, C.T.S.; CYRINO, J.E.P. Regressão segmentada como modelo na determinação de exigências nutricionais de peixes. Scientia Agrícola, v.57, n.4, p.114, 2000.

PREVIERO, C.A.; GROTH, D.; RAZERA, L.F. Dormência de sementes de Brachiaria brizantha (Hochst. Ex A. Rich.) Stapf armazenadas com diferentes teores de água em dois tipos de embalagens. Revista Brasileira de Sementes, v.20, n.2, p.392-397, 1998.

RENARD, C.; CAPELLE, P. Seed germination Ruzizi grass (Brachiaria ruziziensis Germain \& Evrard). Australian Journal of Botany, v.24, p.437-446, 1986.

SMITH, R.L. Seed dormancy in Panicum maximum Jacq. Tropical Agriculture, Trinidad and Tobago, v.56, p.233239, 1979.

TOLEDO, F.F.; CHAMMA, H.M.C.P.; NOVEMBRE, 
A.D.L.C. Germinação de sementes de Panicum maximum Jacq. pré-tratadas com ácido sulfúrico. Scientia Agrícola, v.52, n.1, p.20-24, 1995.

USBERTI, R. Nova metodologia para teste de germinação de sementes de capim-colonião. Casa da Agricultura, v.3, n.1, p.12-16, 1981.
USBERTI, R.; GOMES, R.B.R.; MARTINS, L. Efeito da escarificação com ácido sulfúrico concentrado na germinação de sementes de gramíneas forrageiras (Brachiaria brizantha, B. humidicola e Panicum maximum). In: CONGRESSO BRASILEIRO DE SEMENTES, 9, 1995, Florianópolis Anais... Informativo Abrates, v.5, n.2, p. 118, 1995. 